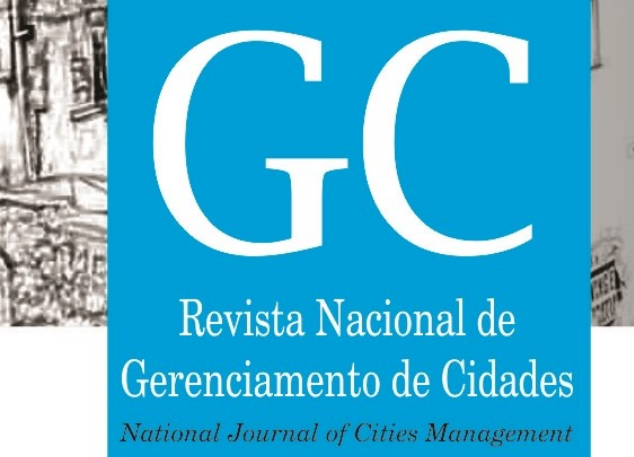

ISSN 2318-8472

v. 04, n. 25,2016

\title{
Espacialização de áreas potencialmente poluídas: proximidade de usos incompatíveis no município de Paranaguá-PR
}

Spatialization of potentially polluted areas: the proximity of the incompatible uses in Paranaguá- $P R$

Espacialización de las áreas potencialmente contaminadas: la proximidad de los usos incompatibles en Paranaguá-PR

Emerson Luis Tonetti

Professor Doutor, IFPR-Paranaguá, Brasil.

emerson.tonetti@ifpr.edu.br

João Carlos Nucci

Professor Doutor, UFPR, Brasil. jcnucci@gmail.com

Simone Valaski

Professora Doutora, UFPR, Brasil.

simone.geo@gmail.com 


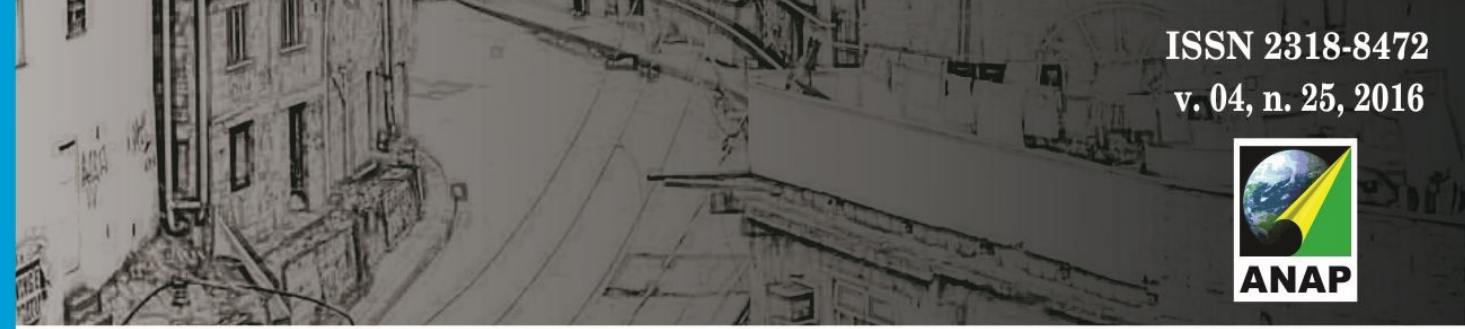

Gerenciamento de Cidades

\section{RESUMO}

A espacialização dos usos potencialmente poluidores chama a atenção para as áreas que possivelmente apresentam restrição para o adensamento populacional urbano devido à baixa qualidade ambiental. Por meio de trabalho de campo foram identificados e espacializados os principais usos e vias com potencialidade para causar poluição em parte da zona urbana do município de Paranaguá. Os dados coletados em campo foram georeferenciados no AutoCAD e no ArcView Gis 3.2, gerando a carta de usos potencialmente causadores de poluição e vias de acesso e suas respectivas áreas de influência na escala 1:15.000. Foram considerados usos com maior potencial para causar poluição, os armazéns, as oficinas, postos de gasolina, entre outros. Usos como mercados de bairro, panificadoras, escolas e afins, foram considerados com menor potencial para causar poluição. Ferrovia, vias rodoviárias com tráfego intenso de veículos pesados e vias com tráfego intenso de veículos leves foram consideradas, relativamente entre si, com potencial alto, médio e baixo para causar poluição, respectivamente. Os resultados demonstraram que as atividades e as vias relacionadas com o Porto D. Pedro II são as principais fontes geradoras de poluição, sendo, portanto, consideradas uma das principais causas da diminuição da qualidade ambiental urbana no segmento urbano estudado.

PALAVRAS-CHAVE: Qualidade Ambiental Urbana. Poluição. Planejamento da Paisagem.

\section{ABSTRACT}

The spatialization of the potentially polluter calls attention to the areas that possibly present restriction to intensification of the urban increasing population density because of the low environmental quality. By means of field work it was identified and spatialized the main uses and roads with the potential to cause pollution in part of the urban area of Paranaguá. The data collected in the field were georeferenced in AutoCAD and ArcView Gis 3.2 generating a map of the potentially polluter uses and access roads and their respective influence areas in the scale $1: 15,000$. It was taken into consideration the uses with the highest potential to cause pollution: the warehouses, the garages, the gas stations, among others. Uses such as neighborhood markets, bakeries, schools and similar were considered with less potential to cause pollution. Railroad, roads with intense traffic of heavy vehicles and roads with intense traffic of light vehicles were compared, relating to each other with high potential, average potential and low potential to cause pollution, respectively. The results showed that the activities and the roads related to $D$. Pedro II Harbor are the main generating sources of pollution. Therefore, they are considered the major causes of the fall of the urban environmental quality in the urban segment studied.

KEYWORDS: Urban environmental quality. Pollution. Landscape Planning.

\section{RESUMEN}

La distribución espacial de los usos con potencial contaminante destaca-se sobre las áreas que posiblemente tienen restricciones para la densidad de población urbana debido a la baja calidad ambiental. A través del trabajo de campo fue posible identificar y distribuir espacialmente los usos principales y las vías con potencial de contaminación de la zona urbana del municipio de Paranaguá. Los datos recogidos en campo fueron georreferenciados en AutoCAD y ArcView GIS 3.2, generando una carta - en escala de 1: 15.000 - de (i) usos que poseen potencial de causar contaminación, (ii) de accesos y sus respectivas áreas de influencia. Los usos que se consideraron con mayor potencial para causar contaminación fueron almacenes, talleres, estaciones de servicio, entre otros. Usos, tales como los mercados de barrio, panaderías, colegios y similares, se considera con menor posibilidad de causar contaminación. Ferrocarril, carreteras con mucho tráfico de vehículos pesados y carreteras con mucho tráfico de vehículos ligeros se considera en relación el uno al otro, con un potencial de alta, media y baja para causar la contaminación, respectivamente. Los resultados mostraron que las actividades y vías relacionadas con Porto D. Pedro II son las principales fuentes de contaminación, y por lo tanto considerase que los mismos son causas principales de la disminución de la calidad del medio ambiente urbano en el segmento urbano estudiado.

PALABRAS CLAVE: Calidad del medio ambiente urbano. Contaminación. Planificación del Paisaje. 


\section{INTRODUÇÃO}

No processo de urbanização, a paisagem vai sendo ocupada por edificações, ruas e toda infraestrutura associada e, em muitos locais, a qualidade do ar, da água e do solo ficam inadequadas para suprir as necessidades do ser humano.

A área urbana do município de Paranaguá, no litoral do Estado do Paraná, apresenta uma população de 140.450 habitantes (IBGE, 2010) e um porto com intensa movimentação de cargas. As atividades e as vias relacionadas com o Porto D. Pedro II, ou porto de Paranaguá como é mais conhecido, estão próximas e se misturam a outros elementos urbanos. Infere-se que os usos e as vias relacionadas com o porto de Paranaguá, além de outros tipos de usos associados a infra-estrutura urbana da área, estejam colaborando com a diminuição da qualidade ambiental por serem fontes importantes de poluição, tensões e/ou conflitos com o uso residencial.

A Lei Orgânica do Município de Paranaguá, nos artigos 203 e 211, afirma que a política urbana deverá promover programas destinados a melhorar as condições ambientais das áreas urbanas e os níveis de saúde da população, para assegurar a todos os cidadãos o direito ao meio ambiente ecologicamente saudável e equilibrado, essencial à qualidade de vida (PARANAGUÁ, 1990).

O Plano Diretor de Desenvolvimento Integrado de Paranaguá aponta como princípios a preservação, a recuperação e a valorização do ambiente e entre suas diretrizes e objetivos consta a elevação da qualidade do ambiente urbano (art. 16, i. IX) (PARANAGUÁ, 2007).

Ainda, segundo o Plano Diretor, entende-se por meio ambiente "a interação dos fatores físicos, químicos e biológicos" (PARANAGUÁ, 2007, LC 68, art. 128, § 1). Desta forma, pode-se deduzir que melhorar a qualidade do ambiente urbano, em Paranaguá, significa melhorar as condições físicas, químicas e biológicas das áreas urbanas do Município.

O objetivo deste estudo foi o de identificar e representar cartograficamente os usos e vias com potencialidade para gerar poluição em um segmento da área urbana do município de Paranaguá.

Esse critério faz parte de um contexto de pesquisa que visou a determinação da Qualidade Ambiental Urbana e a identificação de áreas não adensáveis (TONETTI, 2011), dentro da linha do Planejamento da Paisagem, uma teoria que incorpora a avaliação das potencialidades (limites e aptidões) da natureza e da paisagem para acolher os usos humanos (HAAREN; GALLER; OTT, 2008). 
um som indesejável que fisicamente é de grande complexidade, pois resulta da superposição desarmônica de sons provenientes de várias fontes.

Estudos evidenciaram que todos os bairros centrais de Curitiba apresentaram valores entre 61 e $86 \mathrm{~dB}$ que podem ser considerados críticos ou superiores aos níveis tolerados pela saúde humana (ZORZAL, 2003). Nos cruzamentos de veículos, analisados na cidade de Paranaguá por Teixeira e Tonetti (2008), foram comuns leituras entre 83 e 93 dB. Este tipo de poluição pode trazer prejuízos para a saúde humana.

Neste sentido, Jackson (2003) e Nucci (2008) ponderam sobre a inclusão de usos que incentivam a atividade de veículos motorizados e aumentam a vitalidade econômica em zonas residenciais. Os autores alertam sobre as excessivas emissões tóxicas e sonoras e posicionamse contra esta categoria de pequenas empresas no desenho misto de uso da terra; questões diretamente relacionadas com o planejamento da paisagem de acordo com o grau de compatibilidade entre os diferentes usos do solo em uma área urbanizada.

Barton e Tsourou (2000), em trabalho organizado para a Organização Mundial da Saúde, na busca de garantias de "Qualidade Ambiental" em "Cidades Saudáveis", reforçam a importância do planejamento da distribuição dos usos no meio urbano, deixando claro que existe uma distância mínima e uma máxima entre os diferentes usos e as áreas residenciais (FIGURA 1), o que evitaria, o que prega o Estatuto da Cidade, ou seja, "a proximidade de usos incompatíveis ou inconvenientes" (BRASIL, 2001).

Figura 1 - Proposição de distâncias mínimas e máximas entre a residência e os diferentes tipos de usos como uma medida para se garantir a qualidade ambiental em cidades saudáveis.

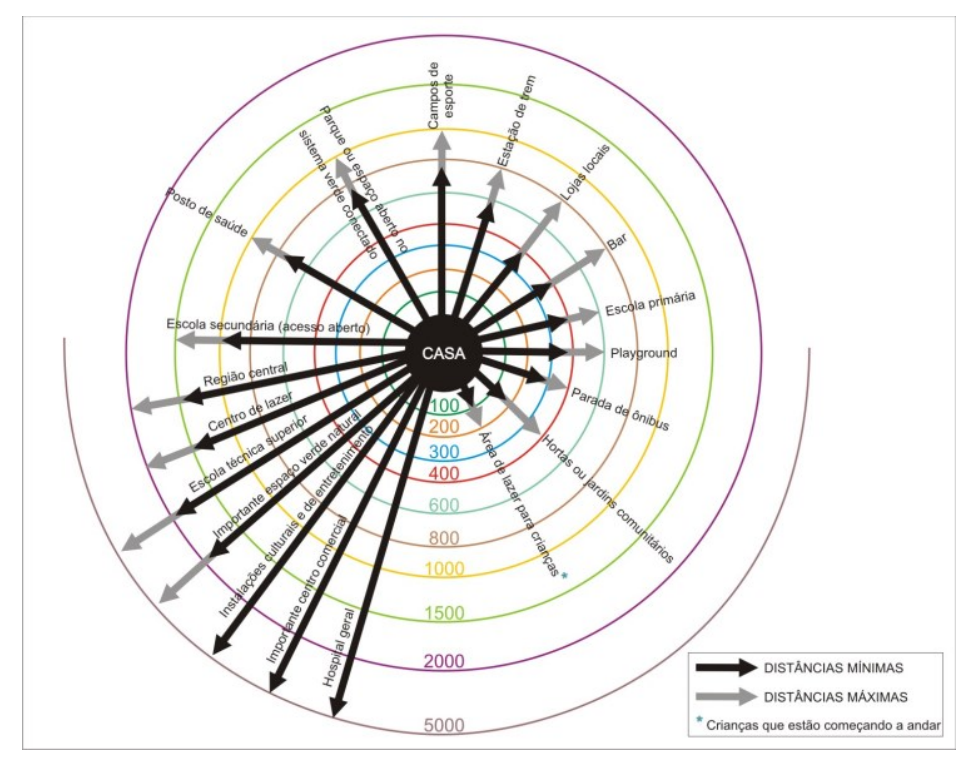

Fonte: Barton e Tsourou, 2000. Tradução e adaptação: Simone Valaski, 2011. 
Observa-se na figura 1 que uma parada de ônibus, por exemplo, deveria ser colocada entre 300 e $400 \mathrm{~m}$ de distância de cada residência, ou seja, ninguém deveria andar mais de $400 \mathrm{~m}$ para encontrar uma parada de ônibus, por sua vez, as paradas de ônibus devem ficar afastadas $300 \mathrm{~m}$ das residências para que sejam evitadas as inconveniências de se viver em contato com diferentes tipos de poluição proveniente dos ônibus. O mesmo se aplica para os bares e comércio local (400-800m), centro de saúde (800-1000m) e assim por diante.

Ao se considerar que há uma distância mínima para separar os locais de moradia de certos usos, como mostra a figura 1, Barton e Tsourou (2000) inferem que esses usos, por exemplo, bares, lojas, posto de saúde, etc., podem ser considerados como potencialmente poluidores, cada qual com suas características.

\section{PROCEDIMENTOS}

A pesquisa foi desenvolvida tendo como base teórica o "Planejamento da Paisagem" (ALEMANHA, 2002; HAAREN, GALLER, OTT, 2008), teoria que incorpora os princípios ecológicos na avaliação das potencialidades (limites e aptidões) da natureza e da paisagem para acolher os usos humanos. O Planejamento da Paisagem apresenta como principal objetivo a busca por uma regulamentação dos usos do solo e dos recursos ambientais, de acordo com princípios da ecologia, salvaguardando a capacidade dos ecossistemas e o potencial recreativo da paisagem, retirando-se o máximo proveito do que os recursos naturais podem fornecer para a melhoria da qualidade ambiental (NUCCl, 2008 e 2010).

O recorte espacial do estudo engloba a parte central da área urbana do Município de Paranaguá, no litoral do Estado do Paraná. A área total do município é de $826,65 \mathrm{~km}^{2}$, a área urbana é de $95,15 \mathrm{~km}^{2}$ e o local de estudo possui 11,64 km2. (FIGURA 2). 
intenso de veículos pesados (caminhões) com médio potencial e as vias com tráfego intenso de veículos leves (automóveis, motos, etc.), com baixo potencial de provocar poluição.

Como a poluição gerada tem comportamento dinâmico, ou seja, desloca-se de seu ponto de origem, para cada via delimitou-se uma área mínima de influência para ambas as margens. 0 limite mínimo de $80 \mathrm{~m}$ foi estabelecido para a malha ferroviária, 50 e $30 \mathrm{~m}$ para as vias com tráfego intenso de veículos pesados e leves, respectivamente, tendo como base as considerações citadas por Spirn (1995, p. 85 - 87).

Essa classificação qualitativa e relativa do uso/ocupação do solo e a inferência da potencialidade para causar poluição, apoiam-se no argumento de que o levantamento direto da poluição no ambiente seria muito mais complexo, demorado, oneroso e de maior dificuldade para o entendimento da comunidade envolvida ( $\mathrm{NUCCl}, 2008$ ), tratando-se, portanto, de um artifício utilizado no Planejamento da Paisagem. Portanto, o que se identifica é o potencial de causar poluição e não se o uso está realmente poluindo, o que exigiria verificação de campo com aparelhagem e técnicas adequadas para cada caso.

O levantamento de campo do tráfego das vias e do uso do solo de cada lote foi realizado nos meses de julho e agosto de 2008 e os dados coletados foram representados na escala 1:5.000, considerando-se apenas o que pôde ser visualizado da calçada, ou seja, não houve verificação do interior de cada lote, seguindo o mesmo procedimento adotado por Nucci (2008).

Os usos de interesse foram destacados de forma independente acarretando uma coleção de cartas temáticas, todas posteriormente geradas na escala de 1:15.000 para a análise dos resultados em gabinete. Não houve perda ou aglutinação de dados durante a mudança da escala da coleta dos dados para a escala utilizada no trabalho de gabinete. Para facilitar a visualização das informações na escala 1:15.000 a delimitação do lote não foi mantida.

O quadro 1 organiza os critérios utilizados na pesquisa. Os valores numéricos foram atribuídos para o cruzamento das várias cartas temáticas, por meio do AutoCAD e do ArcView Gis 3.2, com o intuito de se gerar a carta de qualidade ambiental, um dos objetivos do trabalho de Tonetti (2011). 
QUADRO 1 - Classificação dos usos/ocupação do solo quanto a potencialidade para causar poluição.

\begin{tabular}{|c|c|c|c|}
\hline & Tipologia & $\begin{array}{l}\text { Potencialidade } \\
\text { para causar } \\
\text { poluição }\end{array}$ & Valor \\
\hline \multirow[b]{3}{*}{ Usos } & $\begin{array}{l}\text { residencial, espaços de uso público livres de edificações, } \\
\text { terrenos baldios e cemitérios }\end{array}$ & nenhuma & 0 \\
\hline & $\begin{array}{l}\text { padarias, farmácias, escolas, hospitais, escritórios de } \\
\text { contabilidade, pequenas lojas, mercearias, mercados de } \\
\text { bairro }\end{array}$ & menor & 1 \\
\hline & $\begin{array}{l}\text { armazéns, indústrias, estacionamento, postos de } \\
\text { gasolina, oficinas mecânicas, empresas de manutenção } \\
\text { de equipamentos portuários, serralherias, auto-elétricas, } \\
\text { auto-peças, oficinas de instalação de som automotivo, } \\
\text { funilarias, oficinas de conserto de fogões e geladeiras, } \\
\text { bares e boates }\end{array}$ & maior & 2 \\
\hline \multirow{3}{*}{ Vias } & $\begin{array}{l}\text { tráfego intenso de veículos leves (automóveis, motos, } \\
\text { etc.) - área de influência de } 30 \mathrm{~m} \text { de cada lado. }\end{array}$ & baixo & 1 \\
\hline & $\begin{array}{l}\text { tráfego intenso de veículos pesados (caminhões) - área } \\
\text { de influência de } 50 \mathrm{~m} \text { de cada lado. }\end{array}$ & médio & 2 \\
\hline & Ferrovias - área de influência de $80 \mathrm{~m}$ de cada lado. & alto & 3 \\
\hline
\end{tabular}

Fonte: TONETTI (2011, p. 141)

\section{RESULTADOS E DISCUSSÃO}

As atividades com menor potencial para causar poluição encontram-se em maior densidade na região que corresponde ao centro histórico, no seu entorno e também ao longo de algumas avenidas como Av. Prefeito Roque Vernalha, Av. Gabriel de Lara, Av. Coronel Santa Rita, Av. Manoel Pereira e Maneco Viana (FIGURA 3).

Essas atividades em grande densidade e sem controle na sua distribuição, como o observado nestas áreas, podem ocasionar impactos ambientais negativos que diminuem significativamente a qualidade do ambiente.

Mesmo individualmente, essas atividades podem ocasionar grandes transtornos quando se encontram próximas a residências. É muito conveniente, por exemplo, encontrar uma padaria ou um mercado a uns $100 \mathrm{~m}$ da residência, mas ser vizinho de um desses usos força uma convivência com cheiros, ruídos, poluição visual, trânsito de pedestres e de veículos motorizados que utilizam e abastecem o comércio, quase de madrugada ou até tarde da noite, 


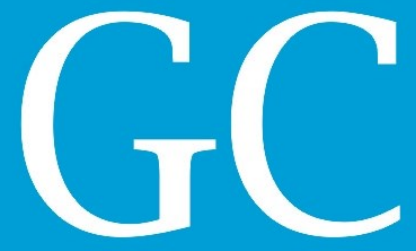

Revista Nacional de

perturbando a tranquilidade dos residentes. Nesses locais o aumento do tráfego com o aumento da poluição acústica e atmosférica são exemplos dessas consequências.

$\mathrm{Na}$ área de estudo há grande concentração dos usos com maior potencial para causar poluição, tais como armazéns, indústrias, estacionamento, postos de gasolina, oficinas mecânicas, empresas de manutenção de equipamentos portuários, serralherias, autoelétricas, venda de autopeças, oficinas de instalação de som automotivo, funilarias, oficinas de conserto de fogões e geladeiras, bares, boates, etc. Essas atividades encontram-se ao longo da Avenida Airton Senna, em parte da Avenida Bento Munhoz da Rocha e da Avenida Coronel Jose Lobo, entre outras. Estes usos ocupam praticamente toda porção norte e noroeste do local de estudo, sendo, geralmente, instalações portuárias ou relacionadas com o porto (FIGURA 3). Muitas dessas atividades funcionam de forma ininterrupta, com utilização constante de equipamentos 'pesados' e elevado fluxo de caminhões e trens, todos com alto potencial para gerar poluição.

Figura 3 - Distribuição do uso e ocupação do solo do local de estudo.

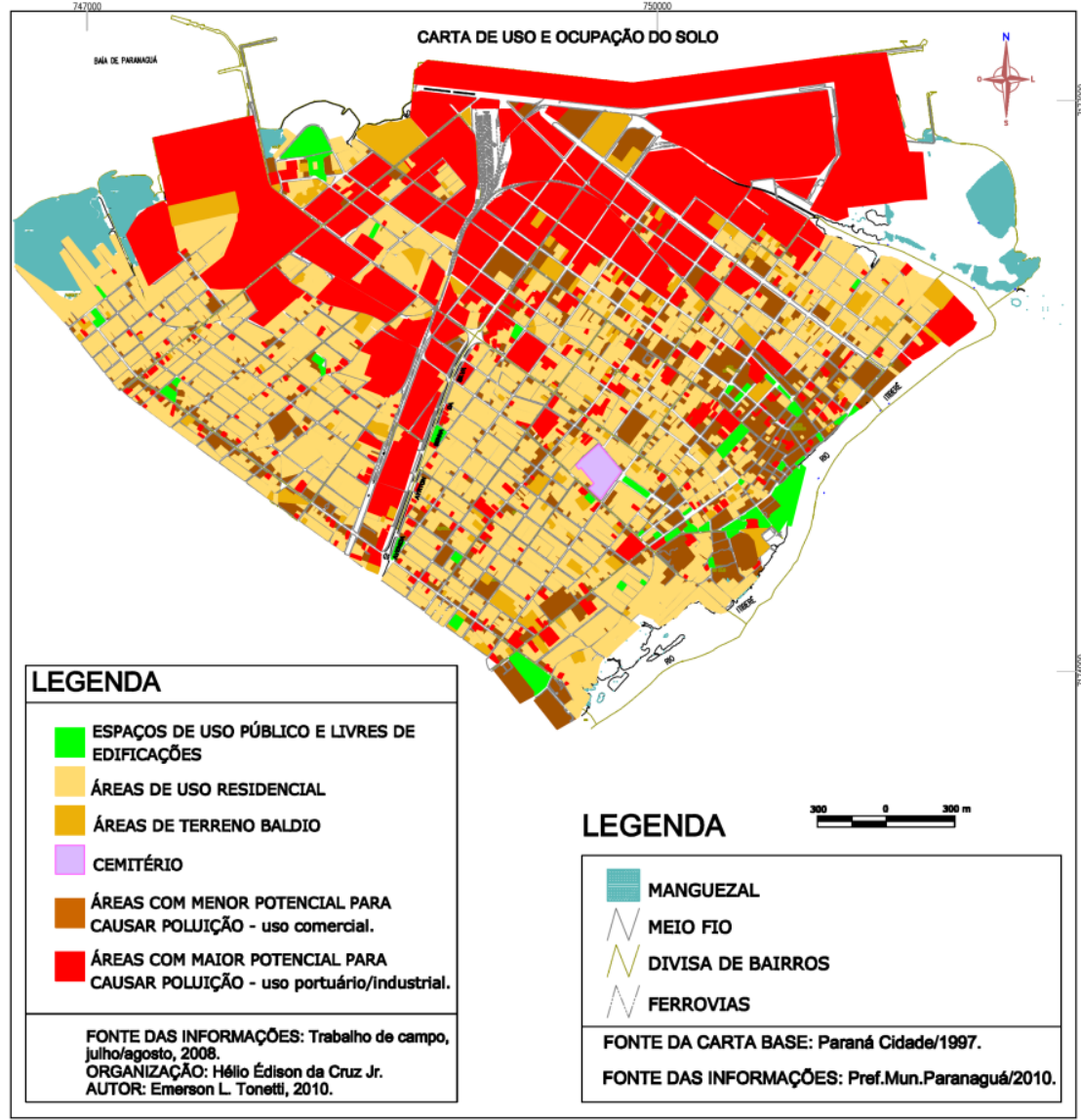

Fonte: Tonetti (2011, p. 147). 


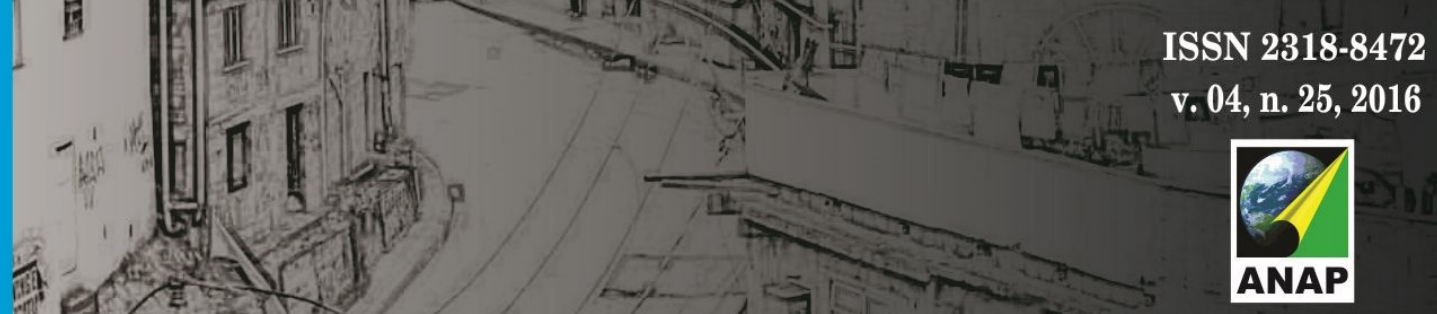

Revista Nacional de Gerenciamento de Cidades

Grandes áreas são usadas como pátio para o armazenamento de containers ou para o estacionamento de veículos destinados a exportação ou importação. Uma destas áreas fica localizada no final da rua Manoel Corrêa e outra no cruzamento da Avenida Coronel Jose Lobo com Avenida Airton Senna da Silva.

Existem muitos armazéns de grãos e de minerais componentes de adubos químicos para a agricultura. Os grãos geram um fluxo de caminhões de diferentes estados e municípios para o porto, enquanto que os minerais geram um fluxo de caminhões para fora do município e um grande fluxo local, para abastecer as empresas que realizam o armazenamento e a mistura destes minerais como a FOSPAR, ANDALI e HERINGER. A primeira localizada no fim da Rua Getúlio Vargas, a segunda na Avenida Airton Senna da Silva e a última na BR 277. Existem alguns armazéns e indústrias de processamento de óleo vegetal, como as empresas Cattalini e a Sadia, localizadas na margem da malha ferroviária e da BR 277, respectivamente.

Na área também são encontrados depósitos de materiais inflamáveis como os da Petrobras, da Cattalini, União Vopak e o Terminal Público de Álcool de Paranaguá do Governo do Estado do Paraná. Estes depósitos encontram-se localizados nas imediações do terminal portuário de inflamáveis do Porto de Paranaguá, nas proximidades do Santuário de Nossa Senhora do Rocio e entre a ferrovia e a Avenida Airton Senna da Silva.

Alguns aglomerados urbanos com uso residencial ficam bem próximos a estes locais, ou seja, a uma distância equivalente a até duas quadras. A esses locais potencialmente perigosos podese adicionar os armazéns de grãos, pois podem produzir e reter uma atmosfera de pó em seu interior, e também produzir gases inflamáveis, podendo adquirir propriedades explosivas (RANGEL JUNIOR, 2007). Essas atividades além da potencial produção de poluição, que reduz a qualidade ambiental, oferecem riscos para a população residente nas áreas próximas, devido a possibilidade de ocorrência de explosões (TONETTI, SCHRÖDER; NUCCI, 2015).

As vias com tráfego intenso de veículos pesados e a ferrovia estão concentradas nas regiões oeste e norte, enquanto que as vias com tráfego intenso de veículos leves encontram-se na região leste. A figura 4 apresenta a carta de vias de acesso e suas respectivas áreas de influência quanto a potencialidade para causar poluição. 


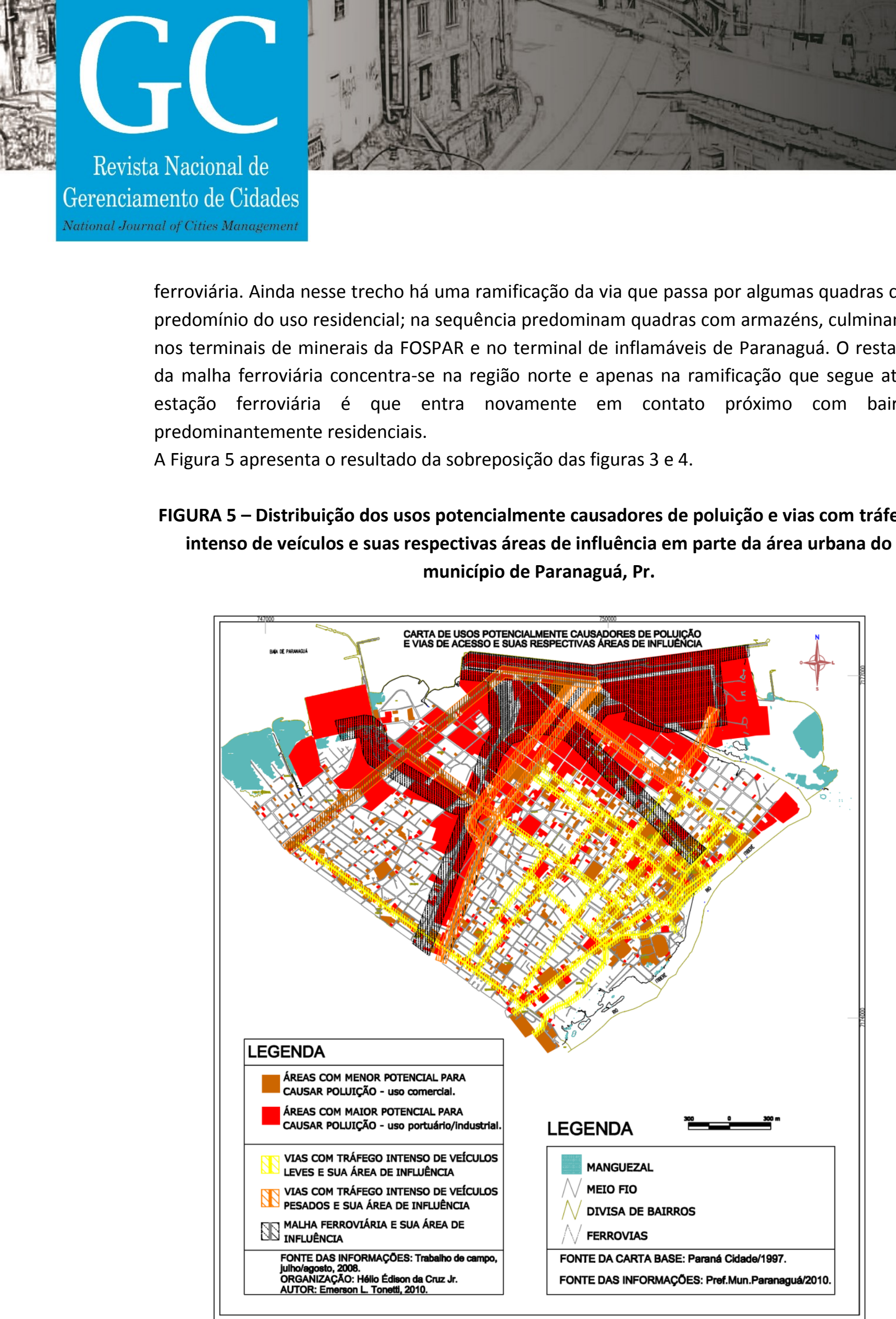

Fonte: os autores. 


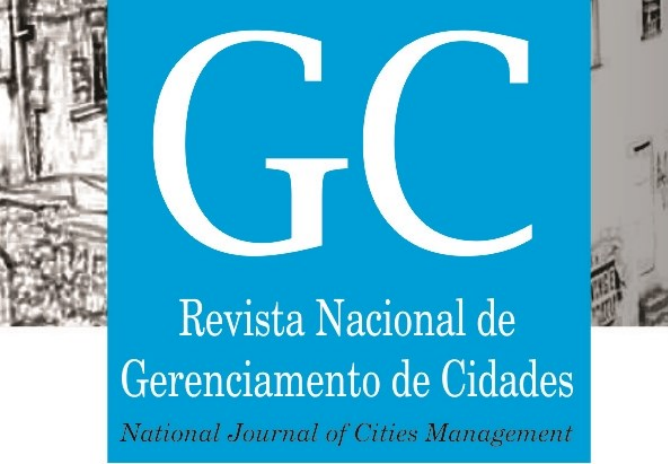

inconvenientes". Assim, espera-se que essa, e outras, diretrizes gerais para o ordenamento urbano sejam devidamente colocadas em prática pelos Planos Diretores municipais.

AGRADECIMENTOS: ao CNPq pela concessão de bolsa de produtividade em pesquisa ao segundo autor.

\section{REFERÊNCIAS}

ALEMANHA. Landscape planning for sustainable municipal development. The German Federal Agency for Nature Conservation (Bundesamt für Naturschutz, BfN). Leipzig: BfN-AS Leipzig field office, 2002.

BARTON, H.; TSOUROU, C. Health urban planning. A WHO guide to planning for people. Londres: Spon Press (em nome da Organização Mundial da Saúde - WHO), 2000, 184p.

BRASIL. Lei Federal no 10.257, de 10 de julho de 2001. Estatuto da Cidade. Disponível em: WWW.planalto.gov.br/ccivil_03/Leis?LEIS_2001/L 10257.htm Acesso em: 20/07/2009.

BRASIL. Lei Federal no 10.932, de 03 de agosto de 2004. Altera o art. 4 da Lei no 6.766, de 19 de dezembro de 1979, que "dispõe sobre o parcelamento do solo urbano e dá outras providências". Disponível em: http://www.planalto.gov.br/ccivil_03/_Ato2004-2006/2004/Lei/L10.932.htm\#art2. Acesso em: 03/12/2014.

BUCCHERI FILHO, A. T. O planejamento dos parques no município de Curitiba, Pr: planejamento sistemático ou planejamento baseado em um modelo oportunista? Caminhos de Geografia, Uberlândia v. 13, n. 41 mar/2012 p. $206-222$.

BUCCHERI FILHO, A. T.; TONETTI, E. L.; Qualidade ambiental nas paisagens urbanizadas. In: Planejamento da Paisagem como subsídio para a participação popular no desenvolvimento urbano. Estudo aplicado ao bairro de Santa Felicidade - Curitiba/PR. / Organização de João Carlos Nucci. Curitiba: LABS/DGEOG/UFPR, 2010, p. 14-25. Disponível em www.geog.ufpr.br/laboratorios/labs/?pg=publicacoes-php Acesso em 20 agosto 2010.

FARIA, G. G.;TONETTI, E. L.; NUCCI, J. C. Qualidade e distribuição das calçadas e ciclovias na área central de Paranaguá (PR) Brasil: uma contribuição à mobilidade na cidade.. In: XV Simpósio Brasileiro de Geografia Física Aplicada, 2013, Vitória. XV Simpósio Brasileiro de Geografia Física Aplicada. Vitória: UFES, 2013. v. 9. p. 31-39.

FELLENBERG, G. Introdução aos problemas da poluição ambiental. São Paulo, EPU/SPRINGER/EDUSP, 1980. 196 p.

FERNANDES, J. C. Acústica e ruídos. Apostila desenvolvida para o curso de graduação em engenharia mecânica da UNESP. 2002. Disponível em <http://www.unesp.br/ jcandido>. Acesso em 20 de abril de 2007.

HAAREN, C. v.; GALLER, C.; OTT, S. Landscape planning. The basis of sustainable landscape development. Federal Agency for Nature Conservation (Bundesamt für Naturschutz). Leipzig: Gebr. Klingenberg Buchkunst, 2008.

HOUGH, M. Naturaleza y ciudad: planificacion urbana y processos ecologicos. Barcelona: G. Gilli, 1998. 315 p. 


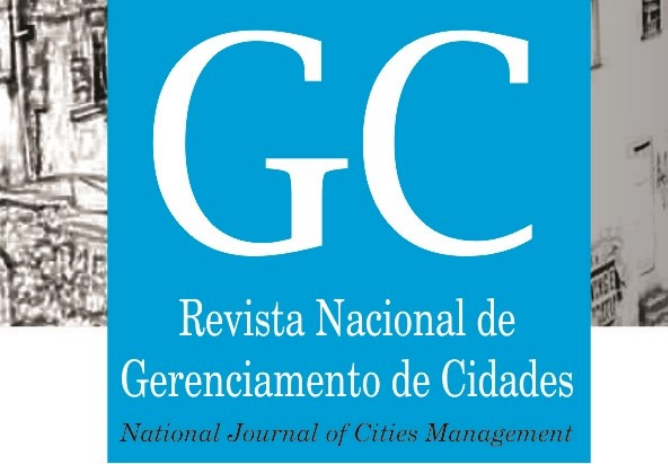

IBGE. Instituto Brasileiro de Geografia e Estatística. Cidades, Paranaguá, 2010. Disponível em: http://www.ibge.gov.br/cidadesat/painel/painel.php?codmun=411820. Acesso em: 12 fevereiro 2011.

JACKSON, L.E. The relationship of urban design to human health and condition. Landscape and Urban Planning 64 (2003) 191-200.

NUCCI, J. C. Qualidade ambiental e adensamento: um estudo de Planejamento da Paisagem do distrito de Santa Cecília (MSP). Tese de doutorado. Universidade de São Paulo. Programa de Pós-Graduação em Geografia Física. 1996.

NUCCI, J. C. Qualidade Ambiental e Adensamento Urbano: um estudo de ecologia e planejamento da paisagem aplicado ao distrito de Santa Cecília (MSP). Curitiba: Edição do autor, 2008 (2aed.). 142p. Disponível em www.geog.ufpr.br/laboratorios/labs/?pg=publicacoes-php Acesso em 15 dezembro 2008.

NUCCI, J. C. Ecologia e Planejamento da Paisagem. In: Douglas Gomes dos Santos; João Carlos Nucci. (Org.). Paisagens Geográficas. Um tributo a Felisberto Cavalheiro. Campo Mourão: Editora da FECILCAM, 2009, p. 50-64. Disponível em

http://www.fecilcam.br/editora/index.php?option=com_content\&task=blogcategory\&id=6\&ltemid=12 Acesso em 28 abril 2010.

PALOMO, P. J. S. La planificación verde em las ciudades. 1 ed. Barcelona: Gustavo Gili, 2005. 326p.

PARANAGUÁ. Lei Orgânica do Município de Paranaguá, 1990. Disponível em

http://www.helts.com.br/paranagua/plano_diretor.php. Consultado em 10 de dezembro de 2008.

PARANAGUÁ. Lei Complementar no 068, de 23 de agosto de 2007. Institui o Plano Diretor de Desenvolvimento Integrado no Município de Paranaguá. Disponível em http://www.helts.com.br/paranagua/plano_diretor.php . Acesso em 10 de dezembro de 2008.

RANGEL JUNIOR, E. Pós: como evitar explosões. Química e Derivados no 464, agosto, 2007. Disponível em: http://www.quimica.com.br/revista/qd464/pos-explosivos1.html Acesso em: 12 fevereiro 2010.

SPIRN, A. W. O Jardim de Granito: A Natureza no Desenho da Cidade. São Paulo, Editora da Universidade de São Paulo, 1995.

TEIXEIRA, J. F.; TONETTI, E. L. Poluição sonora na área urbana de Paranaguá-PR. In: Simpósio Paranaense de Pósgraduação em Geografia, 2008, Ponta Grossa. Anais ... UEPG, Ponta Grossa, 2008: ISBN 978-85-7798-033-8. 20p.

TONETTI, E. L. Potencialidades de adensamento populacional por verticalização das edificações e qualidade ambiental urbana no município de Paranaguá, Paraná, Brasil. 235f. Tese (Doutorado) - Setor de Ciências da Terra, Universidade Federal do Paraná, Curitiba. 2011. Disponível em http://200.17.203.155/index.php?codigo_sophia=285569 Acesso em 12 abril 2011.

TONETTI, E. L.; SCHRÖDER, P. H.; NUCCI, J.C. Risco de explosão: mistura de usos incompatíveis na área urbana de Paranaguá-PR. In:ROSIN, T. A.; ROSIN, T. A. (Orgs). Riscos e vulnerabilidades ambientais. Tupã: ANAP, 2015. p. 119 $-137$. 
